\title{
ANÁLISE DE VIABILIDADE ECONÔMICA DO ESCOAMENTO DA SOJA PRODUZIDA NA CIDADE DE SORRISO - MT ATRAVÉS DOS CORREDORES DE ESCOAMENTO BR-163 E PARANÁ - TIETÊ
}

\section{ANALYSIS OF ECONOMIC AVAILABILITY OF SOYA FLOW PRODUCED IN SORRISO CITY-MT THROUGH OF FLOW CORRIDORS BR-163 AND PARANÁ-TIETÊ}

\author{
Alexsandro Vanzella ${ }^{1}$; Carlos Jaelso Albanese Chaves ${ }^{2}$; Tarcisio Marcelo Menezes ${ }^{3}$; Moysés Simão \\ Kaveski $^{4}$ \\ ${ }^{1}$ Pontifícia Universidade Católica do Paraná - PUCPR - Maringá - Brasil \\ alexvanzella@hotmail.com \\ ${ }^{2}$ Universidade Estadual de Mato Grosso do Sul - UEMS - Ponta Porã - Brasil \\ Jaelso@uems.br \\ ${ }^{3}$ Centro Universitário de Maringá - CESUMAR - Maringá - Brasil \\ tarcisio@interbusiness.com.br \\ ${ }^{4}$ Universidade Estadual de Mato Grosso do Sul - UEMS - Ponta Porã - Brasil \\ moyses@uems.br
}

\begin{abstract}
Resumo
O problema de pesquisa que norteia este estudo fundamenta-se na condição do produtor de soja da cidade de Sorriso do estado de Mato Grosso, possuir poucas alternativas para vender sua produção. Contudo, este estudo busca respostas a seguinte questão: Qual a melhor alternativa para o produtor rural, entregar sua produção na multinacional estabelecida em Sorriso, entregar no Porto de Paranaguá ou no Porto de Santarém? A metodologia adotada se caracteriza como quantitativa. No entanto, foi desenvolvido um estudo de caso, permitindo assim, o conhecimento de maneira ampla e detalhada do processo de escoamento logístico para a safra de soja na cidade de Sorriso. Considerou-se nesse estudo, a produção de 2000 a 2008. Também, foram coletadas informações com uma empresa de transportes de Sorriso, para se compreender o levantamento histórico dos valores de fretes pagos para o modal rodoviário, para o transporte dos grãos, de Sorriso até os portos de Santarém e Paranaguá. Observa-se que, o município de Sorriso está situado na região central de Mato Grosso, no $\mathrm{km} 742$ da rodovia BR-163, no sentido CuiabáSantarém, a $420 \mathrm{~km}$ da capital Cuiabá. Considerando-se a produção da propriedade em estudo, verificou-se que, a viabilidade econômica de o produtor comercializar sua safra de soja no porto de embarque de Paranaguá-PR, possui a melhor vantagem econômica.
\end{abstract}

Palavras-chave: logística; corredor logístico; escoamento de soja.

\section{Introdução}

O Brasil tornou-se uma grande potência do agronegócio mundial, devido a sua produção nas mais diversas cadeias do agronegócio e sua rica biodiversidade. Destacando-se a commodity 
soja, onde é o primeiro exportador do grão, com 32.400 milhões de toneladas e segundo maior produtor mundial, com uma safra de 74.300 milhões de toneladas em 2011/2012, sendo 7,81\% superior à safra passada, perdendo apenas para os EUA (ABIOVE, on-line 2011).

Para Ignácio et al (2009) o Brasil, dispõe de 13\% de toda a água doce disponível no planeta, 388 milhões de hectares de terras agricultáveis férteis, além de produtores rurais experientes, apresentando uma potencialidade e um diferencial competitivo em relação aos outros correntes na participação mundial deste mercado.

A região Centro-Oeste do país é privilegiada pela sua capacidade de produção de grãos, onde o estado do Mato Grosso é caracterizado por cultivar uma área total de 6,4 milhões de hectares de soja (INPE, on-line, 2011), que equivale a 29,1\% da produção total de soja do país (IBGE, online 2011). Obtendo este, uma safra de 20,5 milhões de toneladas de soja registradas em 2010/2011 (INPE, on-line, 2011), e a cidade de Sorriso-MT é responsável por cultivar uma área de 600 mil hectares, com uma produção de 2,232 milhões de toneladas (GRANDE CUIABÁ, on-line 2011).

Devido às distâncias, de $1.700 \mathrm{~km}$ entre Sorriso-MT e Santarém-PA e $2.255 \mathrm{~km}$ entre Sorriso-MT à Paranaguá-PR, a falta de pavimentação para o escoamento da safra e os altos custos com o transporte, verifica-se a necessidade de se conhecer os modais de transporte dessa região e os custos relativos aos corredores de escoamento da produção da soja. O resultado, proporcionárá uma boa oportunidade para o empresário do setor do agronegócio da cidade de Sorriso-MT.

Após analisar alguns dados, Ignácio et al (2009) observam que o Brasil ocupa uma posição de destaque entre os líderes mundiais na produção de soja, além de outros produtos, tais como: milho, açúcar, café, carne bovina e de frango. Entretanto, os bons resultados e as expectativas futuras, poderão estar comprometidos se as dificuldades relacionadas à infraestrutura logística não forem solucionadas.

Diante de tais considerações, observa-se que a questão fundamental deste estudo baseia-se no fato de que o produtor de soja da cidade de Sorriso possuir poucas alternativas para vender sua produção. Contudo, este estudo busca respostas a seguinte incógnita: Qual a melhor alternativa para o produtor rural, entregar sua produção na multinacional estabelecida em Sorriso ou entregar no porto de Paranaguá-PR? Ou ainda, no Porto de Santarém-PA? Diante do problema levando, foi estabelecido o objetivo de: apresentar através de um estudo de viabilidade econômica, a melhor alternatida para o produtor rural da cidade de Sorriso-MT entregar sua produção de soja. Para tanto, considera-se a multinacional estabelecida na cidade, o Porto de Paranaguá-PR e o Porto de Santarém-PA. 


\section{Logística}

A logística empresarial pode ser definida como arte ou ciência responsável pelo fluxo de produtos e informações desde o ponto de produção até o ponto de consumo, buscando a minimização de custos e maximização de lucros (GOMES, 2004). Segundo Magge (1999), logística possui origem francesa do verbo "alojar", onde era utilizado por militares, pelos significados de alojar, transportar e abastecer. De acordo com Gomes e Tortato (2010, p. 201) atualmente, nas organizações o termo logística "é utilizado na descrição das atividades relacionadas com os fluxos de entrada de suprimentos e de saída de produtos e tende a ganhar uma visão integrada entre as empresas à medida que estas planejam suas atividades de forma conjunta, ganhando em eficiência e eficácia".

Novaes (2007) observa que a logística empresarial evolui muito desde seus primórdios e que a logística agrega valor de lugar, de tempo, de qualidade e de informação à cadeia produtiva. Para esse autor, a logística envolve recursos humanos, materiais, tecnológicos e de informação. E ainda, implica na otimização dos recursos, para buscar aumento da eficiência e a melhoria dos níveis de serviço ao cliente. Bader e Savoia (2013) afirmam que, recentemente, a evolução economia brasileira, tem cooperado significativamente para o desenvolvimento da indústria e da tecnologia nacional.

A logística visa proporcionar a melhor rentabilidade aos consumidores e clientes, de forma que consigam obter os bens e serviços com eficiência por meio de planejamento na armazenagem, distribuição e transporte (BALLOU, 1993). Caixeta Filho e Gameiro (2001) apresentam a logística como a administração e manuseio de cargas, visando à otimização da eficiência das operações de transporte e com menor custo, sendo capaz de determinar vantagens de um sistema empresarial.

As variáveis da logística constituem-se em minimizar custos, onde envolvem prazos para carga; descarga; saída e chegada; destino; origem; trajeto; modalidade; embalagem; perdas e outros (CAIXETA FILHO e GAMEIRO, 2001). Por fim, observa-se que a logística envolve toda cadeia de suprimentos. Por cadeia de suprimentos, Francischini e Gurgel (2010, p. 262) consideram a “integração dos processos que formam um determinado negócio, desde os fornecedores originais até o usuário final, proporcionando produtos, serviços, e informações que agregam valor para o cliente". Machline (2011) considera que a cadeia de suprimentos se compromete desde o início até os elos finais da corrente de fornecedores e clientes, possuindo assim, uma visão mais ampla e panorâmica do conceito da logística. 


\subsection{Componentes do processo logístico}

Para a operacionalização dos processos logísticos, ou seja, do ponto de produção ao ponto de consumo, existe o tripé logístico que considera as tarefas de armazenagem, distribuição e transporte.

Armazenagem: Os custos da armazenagem podem ser justificados, pois eles podem ser compensados com os custos de transporte e de produção. Sendo que, uma empresa pode reduzir os seus custos de produção referente aos estoques que absorvem as flutuações dos níveis de produção devido à incerteza do processo de manufatura e pelas variações da oferta e demanda (BALLOU, 1993). Dias (2009) considera que o conceito de armazenagem está sofrendo modificações consideráveis, passando do significado tradicional de empilhamento para a sofisticação atual das estruturas de grande altura, utilizando empilhadeiras de grande elevação, maximizando a utilização da capacidade cúbica e reduzindo o custo do metro cúbico.

Empresas maiores e bem estruturadas nos dias de hoje estão evitando a armazenagem, com finalidades de trabalhar com o just-in-time. Ou seja, trabalhar com o suprimento e a demanda no tempo e na quantidade, de forma que produtos ou insumos diversos cheguem apenas ao momento necessário, não ficando armazenadas por muito tempo (BALLOU, 1993).

Distribuição: Conforme Bertaglia (2009), o processo de distribuição está associado à movimentação física de materias, considerando a existência de um fornecedor e um cliente. Este autor observa que a distribuição varia de produto para produto e que atualmente a distribuição tem recebido especial atenção por se tratar de um processo de suprema importânica devido aos altos custos envolvidos. Francischini e Gurgel (2010) ressaltam que os custos da movumentação das mercadorias e do produto, agregam diretamente no seu custo final.

Este processo é atualmente o foco das empresas devido a seu elevado custo operacional e as oportunidades são muitas. Ou seja, é o processo que tem como objetivo levar o produto acabado até o consumidor. Este item do tripé logístico é o que agrega maior valor ao produto, tendo em vista que o consumidor, seja ele final ou não, está cada vez mais exigente.

O Brasil tem evoluído no aspecto de distribuição, por apresentar numerosos pólos de produção e de consumo, o que gera uma gigantesca mivimentação de mercadorias. Porém, a infraestrutura ainda está centralizada nas rodovias, o que eleva os custos de transporte. Já os países desenvolvidos utilizam meios alternativos para realizar a distribuição de seus produtos, como vias ferroviárias, marítimas e outras (BERTAGLIA, 2009). Hoje existem os centros de distribuições avançados, os quais são de sistemas escalonados, onde o estoque é posicionado em vários elos de uma cadeia de suprimentos. Seu objetivo é atender rapidamente às necessidades dos clientes de determinada área geográfica distantes dos centros produtores (LACERDA, 2009). 
Transporte: $O$ transporte é a transferência de uma determinada mercadoria de um lugar para outro, e sua necessidade está ligada a quem produz e a quem deseja consumir o produto. Sendo este, um item de importante gerenciamento, tendo em vista o seu significativo custo. Referindo-se ao transporte, Bertaglia (2009) observa que, o transporte corresponde á movimentação física do produto, que pode acontecer por várias circunstânicas.

De acordo com Bowersox e Closs (2001) existem dois princípios fundamentais que norteiam as operações e gerenciamentos de transportes: a economia de escala e a economia de distância. A economia de escala é obtida pela diminuição do custo de transporte por unidade de peso com cargas maiores, elas podem ser reduzidas pelo fato de que as despesas fixas de movimentação de uma carga são praticamente as mesmas com um volume ou peso maior ou menor transportado. Já a economia de distância tem como característica a diminuição de custos de transporte pela unidade de distância que é percorrida, ou seja, por exemplo, uma viagem de $1.000 \mathrm{~km}$ com o mesmo peso terá um custo menor que duas viagens de $500 \mathrm{~km}$. Seu custo é o mais elevado com comparação com os outros itens do tripé logístico, chegando a $66 \%$ dos custos logísticos. Isto se resulta da soma dos custos fixos (depreciação, custo oportunidade, salários, impostos e outros) com a grande parcela dos custos variáveis (combustível, manutenção, pedágios e pneus).

\subsection{Modais de transporte}

Modais de transporte são os meios utilizados para transportar a mercadoria, seja da sua fabricação ao ponto de venda, de uma distribuição ou armazém para armazenagem. Contudo, vale lembrar as palavras de Wanke (2010, p. 32) ao afirmar que "os critérios para a escolha do modal de transporte devem sempre levar em consideração aspectos de custos por um lado e características do serviço por outro".

\subsubsection{Modal rodoviário}

Para Rodrigues (2003, p. 49) “o transporte rodoviário é um dos mais simples e eficientes dentre seus pares. Sua única exigência é existirem rodovias. Porém, este modal apresenta um elevado consumo de combustíveis". Segundo Rodrigues (2003), inúmeros estudos realizados indicam que em um raio acima de $500 \mathrm{~km}$ torna-se inviável, devido ao seu elevado consumo de combustível. Entretanto, é mais indicado para distribuições urbanas, onde é mais próximo, ágil e prático. Wanke (2010, p. 33) observa que "o modal rodoviário apresenta pequenos custos fixos, já que a construção e manutenção de rodovias dependem do poder público".

Caixeta Filho e Gameiro (2001) comentam sobre as peculiaridades do modal, em que as rodovias precisam estar em plenas condições de uso, pois este modal é o único que permite o transporte chamado de ponto a ponto, sendo uma função extremamente importante. No entender de Faria e Costa (2011, p. 90), este tipo de modalidade de transporte "é utilizado para cargas pequenas 
e médias, para curtas e médias distâncias, com coleta e entrega de ponto a ponto". Faria e Costa (2011) observam ainda que, o transporte rodoviário oferece uma ampla cobertura, podendo ser caracterizado como flexível e versátil, sendo mais compatível com as necessidades de serviço ao cliente do que outros modais de transporte.

\subsubsection{Modal ferroviário}

O transporte ferroviário apresenta como suas características os custos fixos altos e custos variáveis relativamente baixos (CAIXETA FILHO e GAMEIRO, 2001). No Brasil, o modal ferroviário é muito utilizado quando se trata de deslocamento de grandes toneladas de produtos homogêneos e as distâncias relativamente longas, e, é importante nos casos de conexões de terminais intermodais (RODRIGUES, 2003). Da mesma forma, Faria e Costa (2011, p. 92) compreendem que, este tipo de transporte "é mais apropriado para grandes massas, e torna-se pouco eficiente e muito oneroso para o deslocamento de pequenas quantidades. Normalmente, é utilizado para itens de baixo valor agregado, mas com grandes volumes de movimentação [...] e para longas ou pequenas distâncias, com baixas velocidades".

Existem duas formas de serviços ferroviários, sendo o transportador regular e o privado. $\mathrm{O}$ transportador regular vende seus serviços para qualquer usuário, já o transportador privado pertence a algum usuário particular. Possivelmente todo movimento em ferrovia é feito pelos serviços regulares (BALLOU, 1993). Outra característica interessante deste sistema de transporte é a possibilidade de transportar qualquer tipo de produto, seja líquido ou sólido, isto se dá devido às diversas formas de vagões, que podem ser aberto, fechado, graneleiro ou tanque. Entretanto, o transporte ferroviário não é muito ágil, pois não possui tantas vias como o rodoviário (RODRIGUES, 2003).

\subsubsection{Modal hidroviário}

Este modal é principalmente utilizado para cargas a granel, produtos químicos, areia, carvão, cereais e produtos de alto valor. O custo de transporte é bem relativo neste modal, pois o tempo de

carga e descarga depende de fatores alheios a ele como grande variabilidade de seu percurso. É ainda inviável nas épocas de secas, devido às baixas dos níveis dos rios.

O serviço hidroviário tem sua abrangência limitada, por necessitar da utilização de outro modal combinadamente, a menos que o usuário esteja localizado nas proximidades da hidrovia. Sendo ainda, em média mais lento que a ferrovia (BALLOU, 1993). Para Caixeta Filho e Gameiro (2001) as principais razões de o Brasil não investir significativamente em hidrovias está relacionado aos rios navegáveis não desembocarem nos oceanos, e os que desembocam não passam em grandes centros econômicos. 


\subsubsection{Modal marítimo}

Transporte marítimo é aquele realizado por navios a motor, de grande porte, nos mares e oceanos, podendo ser de cabotagem ou de longo curso. Sua maior vantagem é a capacidade de transportar grandes volumes de mercadoria, com peso elevado, e ainda com um baixo risco de perdas e danos à mercadoria. Entretanto, suas desvantagens encontram-se em sua lentidão para chegar ao destino final, problemas nos portos e sua disponibilidade é influenciada pelas condições meteorológicas (RODRIGUES, 2003).

Observa-se que, os navios possuem diversos tamanhos e afinidades para determinadas mercadorias. Podendo ser convencionais (divisões cobertas e porões) ou mais específicos, podendo ser para cargas secas, com controle de temperatura, granéis líquidos ou sólidos, produtos químicos, etc. (KEEDI, 2000).

\subsubsection{Modal aeroviário}

É um tipo de transporte totalmente diferenciado dos demais modais, tendo em vista que é transportado por vias aéreas, não possui tráfegos intensos e as operações de carga e descarga são terrestres.

Embora seu frete seja o mais elevado em comparação com os demais modais devido a seus altos custos variáveis (combustível, manutenção, etc.) e custos fixos elevados também (aeronaves e manuseios), sua procura tem sido crescente pelos usuários, por causa de sua agilidade, rapidez e maior eficiência, segurança, redução de custos com estoque (RODRIGUES, 2003). Este tipo de transporte é utilizado em cargas de alto valor agregado, como produtos eletrônicos e produtos com alto grau de perecibilidade, como frutas nobres ou flores. Seu frete é calculado sob o peso ou volume da mercadoria. Isto ocorre devido ao seu custo ser três vezes maior que o rodoviário e quatorze quando comparado com o ferroviário (BALLOU, 1993). Faria e Costa (2011, p. 93) explicam que "o transporte aéreo, tendo em vista seus custos elevados, é utilizado somente em circunstâncias especiais, que podem justificar-se por apresentar um nível de perdas baixo tal como, por exemplo, para produtos de alto valor [...]".

\subsubsection{Modal dutoviário}

É transportado por gravidade ou pressão mecânica, através de dutos planejados e projetados para os determinados produtos à que se destina transportar. É um transporte bem limitado, mais destinado a produtos líquidos e gases em grandes volumes. Seu transporte é bem lento, porém trabalha sem parar, 24 horas por dia e sete dias por semana. Com relação aos custos, o custo variável é extremamente baixo por não ter despesas com mão de obra em grande escala, já o fixo é mais elevado, devido à construção e capacidade de bombeamento (RODRIGUES, 2003). Da mesma forma, Wanke (2010, p. 33) considera que, no modal dutoviário “os custos fixos são mais elevados, 
em função de direitos de passagem, construção, estações de controle e capacidade de bombeamento. Em contrapartida, apresenta os custos fixos mais baixos, muitas vezes desprezíveis”. Sobre esse modal, Faria e Costa (2011, p. 94) observam que "refere-se aos transportes de produtos por meio de dutos subterrâneos e ainda não é amplamente utilizada em todos os segmentos da economia, pois sua utilização é restrita a produtos em estado gasoso, líquido ou pastoso [...]”.

Os principais produtos transportados nesse modal são: o petróleo cru e os seus produtos derivados com maiores valores agregados. Existem estudos buscando a viabilização de transportar granéis sólidos. Entretanto, possui um baixo potencial de utilização no transporte das commodities (RODRIGUES, 2003). Apresenta também, uma importante vantagem, que é a sua confiabilidade, pois os fatores externos não alteram o seu transporte eficiente, sendo independente de tempos e fatores meteorológicos. Entretanto, como desvantagem possui uma lentidão para transportar, o que torna inviável o uso para transporte de perecíveis.

\subsection{Multimodalidade e intermodalidade}

O objetivo da multimodalidade e intermodalidade ou combinações dos modais de transporte é a busca por uma otimização dos recursos de transporte nas suas fases de física e de planejamento e operação (BERTAGLIA, 2003).

Para Bertaglia (2003) o transporte multimodal ou o intermodal são elementos facilitadores nos processos de importação e exportação, uma vez que, pode ser aproveitado o que cada modal de transporte tem de melhor, visando à redução de custos e aumentando o nível de serviço.

Pode-se dizer que, são ferramentas para o tomador de decisões, onde analisa a melhor opção a ser utilizada e quais modais que podem suprir as necessidades que o transporte exige, obtendo o menor custo e a maior rapidez.

Multimodalidade trata-se da combinação de dois ou mais modais de transporte integrados em um escoamento de mercadorias (RODRIGUES, 2003). Este sistema de transporte é considerado competitivo, eficiente e fundamental para o crescimento econômico (CAIXETA FILHO e GAMEIRO, 2001).

A intermodalidade tem como finalidade agregar valores a cada modal, tanto pelo serviço, quanto pelo custo. Caixeta Filho e Gameiro (2001) entendem que a opção de transporte intermodal, ainda não é considerada eficaz, pois a questão estrutural e cultural é um processo lento e que só será eficiente, realmente, quando as opções ferroviárias e hidroviárias se integrarem à rodoviária.

\subsection{Corredores de escoamento}

A produção de grãos brasileira tem-se deslocado para áreas cada vez mais distantes dos grandes centros do Sudeste e Sul do país nas últimas décadas, o que fez viabilizar o desenvolvimento dos corredores de escoamento em direção ao Norte do país, os quais apenas 
recentemente passaram a receber a atenção devida. Um exemplo representativo é a hidrovia do rio Madeira, que exporta a soja em grãos da região da Chapada dos Parecis (noroeste de Mato Grosso) e de Rondônia (região de Vilhena) pelo porto de Itacoatiara-AM (CAIXETA-FILHO e GAMEIRO, 2001).

A visão moderna de corredor de escoamento evoluiu de simples vias de transporte para uma abordagem logística que complementa as cadeias de suprimento que ocupam os espaços econômicos pré-definidos. Ou seja, os fluxos de comércio encontram sistemas de transporte aptos a suportar a movimentação de produtos, compreendendo condições de armazenamento e distribuição, espaço de distribuição, sistemas de transportes e condições de acessibilidade aos mercados locais, regionais, nacionais e externos (LEMOS e MARTINS, on-line, 2011).

Nexte trabalho, verificou-se que corredores de escoamento são rotas existentes ou a serem desenvolvidas com objetivo a desempenhar o menor custo possível e com a maior economia de tempo possível para escoar as safras de determinadas regiões, onde são utilizados para tanto, os sistemas de intermodalidade e multimodalidade de transportes até o porto de embarque da mercadoria para obter um melhor desempenho, ou mesmo o sistema unimodal, que ocorre na maioria das vezes pelo modal rodoviário devido à falta de opções logísticas.

\subsubsection{Corredor BR-163}

O corredor BR-163 abrange o Norte de Mato Grosso até Itaituba-PA e o Rio Tapajós até o Porto de Santarém-PA. Este trajeto é feito pelo modal rodoviário, através da rodovia BR-163, observa-se que não se encontra, amplamente disponível nesse percurso, o transporte hidroviário, porém esta rodovia ainda não se encontra totalmente pavimentada. Os estados em que compreendem o corredor BR-163 são o Mato Grosso, Pará e Amazonas.

O corredor rodovia BR-163/364 liga Cuiabá-MT a Porto Velho-RO, que dá acesso ao rio Madeira e ao rio Amazonas. Essa hidrovia do rio Madeira destina o escoamento até o porto de Itacoatiara, onde existe um terminal graneleiro privado, com destino ao mercado Europeu (CAIXETA-FILHO e GAMEIRO, 2001).

A BR-163 possui pavimentação em $781 \mathrm{~km}$ e os demais $975 \mathrm{~km}$ ainda não estão pavimentados. Estes $781 \mathrm{~km}$ que estão pavimentados, embora se encontre em péssima conservação, correspondem até a cidade de Guarantã do Norte-MT, entrando no estado do Pará por vias de estradas de chão.

\subsubsection{Corredor Paraná-Tietê}

A hidrovia Paraná-Tietê compreende $600 \mathrm{~km}$ do rio Tietê, canalizado desde o terminal de Conchas até a foz no rio Paraná, ligando a região Sul, Sudeste e Centro-Oeste do país. 
Este corredor abrange o complexo hidroviário dos rios Tietê, Paraná e Paraguai, com um potencial de integração regional entre os estados de São Paulo, Paraná, Mato Grosso do Sul, Mato Grosso, Goiás e Triângulo Mineiro. Possui 2.400 km, sendo uma das principais ligações entre o Centro-Oeste e o Porto de Santos.

O porto de Paranaguá está localizado em um ponto estratégico em relação às regiões Sudeste e Sul do país. Sua área de influência compreende o estado do Paraná, Santa Catarina, e São Paulo, Mato Grosso do Sul, Mato Grosso e o Paraguai, além de parte do Rio Grande do Sul e Argentina (CAIXETA FILHO e GAMEIRO, 2001).

Contudo, o porto de Paranaguá está mais próximo para as cargas originadas no Paraná, Santa Catarina e no Paraguai, enquanto o porto de Santos apresenta menor distância para as cargas oriundas da região Centro-Oeste, Minas Gerais e São Paulo (CAIXETA FILHO e GAMEIRO, 2001). Entretanto, mesmo sendo maior a distância entre a região Centro-Oeste e porto de Paranaguá, segundo Caixeta Filho e Gameiro (2001) ainda, torna-se mais viável a opção Paranaguá.

\section{Metodologia de pesquisa}

Este estudo se fundamentou na abordagem quantitativa. No entender de Richardson (2011), a pesquisa quantitativa busca, em princípio, garantir a precisão dos resultados evitando distorções de análise e interpretação, e ainda, possibilita, conseqüentemente, uma margem de segurança quanto as inferências. O método quantitativo é freqüentemente aplicado em pesquisas descritivas. Sendo assim, e de acordo com os objetivos apresentados, este estudo, também compreendeu a pesquisa descritiva. Este tipo de estudo é utilizado quando o objetivo do pesquisador consiste em descrever situações, acontecimentos, e feito isso, procura elucidar como se manifesta tal fenômeno (RICHARDSON, 2011).

No entanto, foi adotado o estudo de caso para o desenvolvimento da presente pesquisa, permitindo assim o conhecimento de maneira ampla e detalhada do processo de escoamento logístico para a safra de soja em grãos na cidade de Sorriso-MT.

Para a coleta de dados foi necessário entrar em contato com o produtor rural para o levantamento de sua produção de soja. Considerou-se nesse estudo, a produção de 2000 a 2008. Buscou-se também, compreender a forma de comercialização, bem como os meios disponíveis para a região escoar a sua produção agrícola. Também, foram coletadas informações com a empresa de transportes Rodogrande, unidade de Sorriso, compreendendo o levantamento histórico dos valores de fretes pagos para o modal rodoviário, para o transporte dos grãos até os portos de Santarém e Paranaguá. Por fim, ocorreu a necessidade do levantamento de dados na empresa Cargil de SorrisoMT, com a finalidade de se conhecer os preços históricos pagos à soja, em Sorriso, Paranaguá e Santarém. Os documentos coletados representam os registros anuais e mensais de produção, 
comercialização, cotações de preços da soja, disponíveis em sites e registros internos de empresas colaboradoras.

A análise dos dados se fundamentou na forma de análise quantitativa, com o propósito de processar e transformar os dados em informações que demonstrasse a quantidade média de sua produção e os valores médios recebidos com a comercialização de sua produção, valores econômicos para o empresário rural, através de cálculos de médias de custos com transporte e de viabilidade econômica de uma gestão logística, tudo com o propósito de maximizar o lucro.

\subsection{Considerações sobre a cidade de Sorriso-MT}

O município de Sorriso está situado na região central de Mato Grosso, no km 742 da rodovia BR-163, no sentido Cuiabá-Santarém, a 420 km da capital Cuiabá. A cidade de Sorriso conta com uma área de 934.600 hectares (PREFEITURA DE SORRISO, on-line, 2011) e em média uma área plantada com soja de 600 mil hectares (GRANDE CUIABÁ, on-line, 2011).

A soja é uma cultura milenar, porém, possui registro do primeiro cultivo no Brasil na década de 1914, no município de Santa Rosa-RS. Em 1970 menos de 2\% era o percentual de produção da região Centro-Oeste, passando para 20\% em 1980 e, em 2003 já se registrava aproximadamente $60 \%$ da produção nacional (EMBRAPA, on-line, 2011). Atualmente os principais estados brasileiros produtores de soja são, respectivamente, Mato-Grosso, Paraná, Rio Grande do Sul, Goiás e Mato-Grosso do Sul (CI-SOJA, on-line, 2011).

Dos principais Estados produtores de soja, o estado do Mato Grosso no ano 2010/2011 teve uma safra de 20,5 milhões de toneladas (INPE, on-line, 2011). Considerando esta safra matogrossense, a cidade de Sorriso ficou com a quantidade de 2,232 milhões de toneladas (GRANDE CUIABÁ, on-line 2011).

A cidade de Sorriso, para título de demonstrar tamanha é sua relevância na produção da oleagenosa soja e sua grande necessidade de investimentos na área logística para escoamentos, verifica-se que sua produção é maior do que diversos países, como são exemplos, a Bolívia e o Uruguai, que produzem, respectivamente, 2,10 milhões de tolenadas e 1,55 milhões de toneladas no ano de 2009/2010 (CI-SOJA, on-line, 2011).

\section{Coleta dos dados}

\subsection{Produção da soja}

O produtor X da cidade de Sorriso, possui uma propriedade rural com um tamanho de 2.500 hectares, os quais estão disponíveis e agricultáveis apenas 1.000 hectares. Sua atividade agrícola é inteiramente voltada à cultura da soja, e sua produção é vendida para a multinacional Bunge de 
Sorriso. Observa-se que, a empresa rural analisada está localizada a $30 \mathrm{~km}$ da cidade, onde a estrada é integralmente sem pavimentação asfáltica.

A Tabela 1 apresenta a produção e produtividade histórica da soja obtida na empresa rural analisada e, a quantidade de carretas necessárias para o transporte desta produção, levando em consideração 37 toneladas cada veículo.

Tabela 1 - Produção de soja

\begin{tabular}{ccccc}
\hline Ciclo & Produtividade sc/há & Produção/sc & Produção/ton. & Qtde. Carretas/ 37 ton. \\
\hline $2000 / 2001$ & 49 & 49.000 & 2.940 & 80 \\
$2001 / 2002$ & 48 & 48000 & 2.880 & 78 \\
$2002 / 2003$ & 50 & 50.000 & 3.000 & 81 \\
$2003 / 2004$ & 48 & 48.000 & 2.880 & 78 \\
$2004 / 2005$ & 53 & 53.000 & 3.180 & 86 \\
$2005 / 2006$ & 53 & 53.000 & 3.180 & 86 \\
$2006 / 2007$ & 51 & 51.000 & 3.060 & 82 \\
$2007 / 2008$ & 51 & 51.000 & 3.060 & 82 \\
\hline Média & 50,37 & 50.375 & 3.022 & 82 \\
\hline
\end{tabular}

Fonte: Autoria própria (2008)

\subsection{Preço da soja}

Para se analisar a viabilidade de o produtor de soja $\mathrm{X}$ da cidade de Sorriso - MT comercializar sua safra na própria cooperativa localizada nas proximidades ou escoar para os portos de Paranaguá-PR e Santarém-PA, torna-se necessário a avaliação de um histórico do preço médio da soja, das opções que possui, conforme apresentadas na Tabela 2. Os números apresentados na Tabela 2 foram obtidos, após um levantamento dos preços da soja diários, e posteriormente feitos uma média dos três pontos de comercialização.

Tabela 2 - Preços médios da soja

\begin{tabular}{cccc}
\hline Mês/2008/média & Paranaguá/R $\mathbf{R} / \mathbf{s c}$ & Santarém/R\$/sc & Sorriso/R\$/sc \\
\hline Janeiro & 48,50 & 51,00 & 36,50 \\
Fevereiro & 51,50 & 54,00 & 39,20 \\
Março & 46,50 & 45,70 & 35,00 \\
Abril & 47,00 & 47,70 & 36,00 \\
Maio & 46,00 & 47,90 & 36,80 \\
Junho & 55,50 & 56,80 & 43,90 \\
Julho & 50,00 & 49,90 & 38,60 \\
Agosto & 48,30 & 50,00 & 38,00 \\
Setembro & 48,00 & 47,70 & 39,50 \\
Média total & 49,03 & 50,08 & 38,17 \\
\hline
\end{tabular}

Fonte: Cargil (2008)

\subsection{Custos de transporte}

A Tabela 3 traz um histórico dos custos com o transporte em toneladas de soja para escoar a safra do produtor $\mathrm{X}$ para os portos de embarque deste estudo e do transporte local, da propriedade até o armazém da empresa. Onde, a primeira rota é a opção Sorriso - MT com destino à ParanaguáPR. A segunda será o ponto de origem Sorriso - MT a Santarém-PA. Como terceira rota, será 
apenas o transporte dentro do município de Sorriso - MT, ou seja, da propriedade do produtor X para o armazém de destino.

Tabela 3 - Custos históricos com transporte

\begin{tabular}{cccc}
\hline Mês & Sorriso - Santarém & Sorriso - Paranaguá & Sorriso - Sorriso \\
$\mathbf{0 1 / 2 0 0 8}$ & $\mathrm{R} \$ 236,60 /$ ton & $\mathrm{R} \$ 182,00 /$ ton & $\mathrm{R} \$ 11,67 /$ ton \\
$\mathbf{0 2 / 2 0 0 8}$ & $\mathrm{R} \$ 240,50 /$ ton & $\mathrm{R} \$ 185,00 /$ ton & $\mathrm{R} \$ 11,86 /$ ton \\
$\mathbf{0 3 / 2 0 0 8}$ & $\mathrm{R} \$ 240,50 /$ ton & $\mathrm{R} \$ 185,00 /$ ton & $\mathrm{R} \$ 11,86 /$ ton \\
$\mathbf{0 4 / 2 0 0 8}$ & $\mathrm{R} \$ 243,10 /$ ton & $\mathrm{R} \$ 187,00 /$ ton & $\mathrm{R} \$ 11,99 /$ ton \\
$\mathbf{0 5} / \mathbf{2 0 0 8}$ & $\mathrm{R} \$ 228,80 /$ ton & $\mathrm{R} \$ 176,00 /$ ton & $\mathrm{R} \$ 11,28 /$ ton \\
$\mathbf{0 6 / 2 0 0 8}$ & $\mathrm{R} \$ 228,80 /$ ton & $\mathrm{R} \$ 176,00 /$ ton & $\mathrm{R} \$ 11,28 /$ ton \\
$\mathbf{0 7 / 2 0 0 8}$ & $\mathrm{R} \$ 223,60 /$ ton & $\mathrm{R} \$ 172,00 /$ ton & $\mathrm{R} \$ 11,02 /$ ton \\
$\mathbf{0 8} / \mathbf{2 0 0 8}$ & $\mathrm{R} \$ 221,00 /$ ton & $\mathrm{R} \$ 170,00 /$ ton & $\mathrm{R} \$ 10,89 /$ ton \\
$\mathbf{0 9} / \mathbf{2 0 0 8}$ & $\mathrm{R} \$ 221,00 /$ ton & $\mathrm{R} \$ 170,00 /$ ton & $\mathrm{R} \$ 10,89 /$ ton \\
$\mathbf{1 0 / 2 0 0 8}$ & $\mathrm{R} \$ 214,50 /$ ton & $\mathrm{R} \$ 165,00 /$ ton & $\mathrm{R} \$ 10,57 /$ ton \\
\hline Média & $\mathrm{R} \$ 229,84 /$ ton & $\mathrm{R} \$ 176,80 /$ ton & $\mathrm{R} \$ 11,33 /$ ton \\
\hline
\end{tabular}

Fonte: Transportadora Rodogrande (unidade Sorriso) (2008)

\section{Análise dos dados}

Conforme a Série Agronegócios (on-line, 2011) o Brasil é extremamente competitivo na produção de soja devido ao baixo custo da mão de obra, alta disponibilidade de terras e condições metereológicas favoráveis, além de estar na vanguarda mundial da tecnologia de produção dessa oleaginosa nas regiões tropicais. Contudo, esta competitividade está limitada aos gargalos logísticos, como se cita, por exemplo, as condições de transporte das rodovias BR-163 e BR-158 e a pouca estrutura de armazenagem de soja. Para tanto, nota-se que, conforme a Tabela 4, a alta produção de uma propriedade de apenas 1.000 hectares, e com um elevado custo de transporte rodoviário, chegando até $\mathrm{R} \$ 13,79$ por saca de soja, a qual sua cotação é de $\mathrm{R} \$ 50,08$. Observa-se, ainda, o tamanho da disproporção para o valor de transporte rodoviário para os portos de Paranaguá e Santarém, visto que deveria ser inverso estes números em virtude de o porto de Santarém ser mais próximo a cidade de Sorriso e ambos serem realizados pelo modal rodoviário.

Tabela 4 - Custos com frete por sacas de soja

\begin{tabular}{cccc}
\hline Rota & Frete rodoviário/sc & Produção soja/sc & Total frete \\
\hline Sorriso (MT) - Paranaguá (PR) & $\mathrm{R} \$ 10,61 / \mathrm{sc}$ & $50.375 \mathrm{sc}$ & $\mathrm{R} \$ 534.478,75$ \\
Sorriso (MT) - Santarém (PA) & $\mathrm{R} \$ 13,79 / \mathrm{sc}$ & $50.375 \mathrm{sc}$ & $\mathrm{R} \$ 694.471,25$ \\
Sorriso (MT) - Sorriso (MT) & $\mathrm{R} \$ 0,68 / \mathrm{sc}$ & $50.375 \mathrm{sc}$ & $\mathrm{R} \$ 34.255,00$ \\
\hline Fonte: Resultados da pesquisa & & &
\end{tabular}

Fonte: Resultados da pesquisa

A Tabela 4 apresenta os custos com o frete rodoviário por saca de soja e o total deste frete para toda a produção de soja. A primeira, Sorriso-MT com destino a Paranaguá-PR o produtor terá um custo com frete de $\mathrm{R} \$ 534.478,75$ para o transporte de toda a sua produção de soja. Na segunda opção, Sorriso-MT com destino a Santarém-PA o custo com transporte será de R \$ 694.471,25. Já na terceira alternativa, será o transporte da propriedade rural ao armazém de destino, no caso a Bunge, que possui um custo de $\mathrm{R} \$ 34.255,00$. 
$\mathrm{Na}$ Tabela 5, encontra-se a análise dos do preço dos fretes em sacas de soja perante o preço médio da saca de soja de cada ponto de comercialização, fazendo um comparativo dos dados apresentados.

Tabela 5 - Custos totais com frete para o escoamento

\begin{tabular}{ccccc}
\hline Rota & $\begin{array}{c}\text { Produção } \\
\text { Média/sc/1000ha }\end{array}$ & Preço frete/sc & $\begin{array}{c}\text { Custo total com } \\
\text { frete }\end{array}$ & $\begin{array}{c}\text { Preço médio da } \\
\text { soja }\end{array}$ \\
\hline Sorriso a Sorriso & 50.375 & $\mathrm{R} \$ 0,68 / \mathrm{sc}$ & $\mathrm{R} \$ 34.255,00$ & $\mathrm{R} \$ 38,17$ \\
Sorriso a Santarém & 50.375 & $\mathrm{R} \$ 13,79 / \mathrm{sc}$ & $\mathrm{R} \$ 694.671,25$ & $\mathrm{R} \$ 50,08$ \\
Sorriso a Paranaguá & 50.375 & $\mathrm{R} \$ 10,61 / \mathrm{sc}$ & $\mathrm{R} \$ 534.478,75$ & $\mathrm{R} \$ 49,03$ \\
\hline
\end{tabular}

Fonte: Resultados da pesquisa

Na Tabela 6, verifica-se a importância de um estudo logístico para o transporte, tendo em vista sua grande porcentagem que incide no valor final do produto. Os valores gastos com frete para o escoamento da safra do produtor são extremamente altos, causando impacto a todos, podendo chegar até $27,54 \%$ de sua produção neste estudo.

Lemos e Martins (on-line, 2011) compreendem que a visão moderna de corredores de escoamento vem a evoluir com os tempos atuais, que vem a ser analisadas e definidas melhores oportunidades ou caminhos a serem percorridos para melhor armazenamento, transporte ou distribuição. Para tanto, pela Tabela 6 o valor total do frete causa impacto ao relacioná-lo com a receita obtida pela comercialização da safra, onde mesmo assim precisa-se de melhores estudos de viabilidades para o escoamento da safra da cidade de Sorriso, o qual demonstra ser a rodovia BR163.

Tabela 6 - Valor final da safra

\begin{tabular}{ccccc}
\hline Local de venda & Valor/venda da safra & Valor total do frete & Receita ao produtor & \% frete \\
\hline Sorriso & $\mathrm{R} \$ 1.922 .813,75$ & $\mathrm{R} \$ 34.255,00$ & $\mathrm{R} \$ 1.888 .558,75$ & $1,78 \%$ \\
Paranaguá & $\mathrm{R} \$ 2.487 .537,05$ & $\mathrm{R} \$ 534.478,75$ & $\mathrm{R} \$ 1.953 .058,30$ & $21,49 \%$ \\
Santarém & $\mathrm{R} \$ 2.522 .780,00$ & $\mathrm{R} \$ 694.671,25$ & $\mathrm{R} \$ 1.828 .108,75$ & $27,54 \%$ \\
\hline
\end{tabular}

Fonte: Resultados da pesquisa

Na Tabela 6, verifica-se que o custo logístico de transporte, que acabaram sendo maiores que os apresentados na Tabela 1, e que de acordo com Lacerda (2009), indica a relevância dos estudos logísticos em uma organização rural. Observa-se que, os valores de comercialização da safra do produtor da cidade de Sorriso-MT apresentados na Tabela 6 não estão inclusos as perdas no transporte, devido à má conservação de rodovias, mas leva-se em consideração que a produção total encontra-se disponível para a comercialização no porto de embarque. Estas perdas no transporte segundo dados da CONAB (on-line, 2011), representam um grande gargalo para o agronegócio.

Pensando em perdas de soja no transporte, verifica-se, conforme os dados do INPE (on-line, 2011) que a área total do cultivo da soja no estado do Mato-Grosso aproxima-se a 6,4 milhões de hectares, sendo que, de acordo com Correa e Ramos (on-line, 2011), do total da produção de soja na região Centro-Oeste, 67 \% de seu transporte são realizados pelo modal rodoviário. O que mesmo 
com as vantagens competitivas deste modal apresentadas por Rodrigues (2003), suas desvantagens estão representadas pelo elevado custo que incide diretamente no preço final da soja.

Na Tabela 7, compara-se o valor recebido da comercialização da safra com a distância percorrida em $\mathrm{km}$ e seu tempo de transporte. O que demonstra que, a comercialização em Paranaguá-PR, mesmo possuindo a maior distância, é o melhor valor recebido entre as opções apresentadas nesse estudo. No caso da comercialização na cidade de Sorriso, o tempo de transporte é relativamente insignificante, porém não seria economicamente viável ao produtor $\mathrm{X}$ quando comparado com o valor que receberia no porto de embarque de Paranaguá-PR (maior receita recebida das três opções). Já no porto de Santarém-PA o tempo de viagem é mais curto devido a sua menor distância, salvo em casos de épocas de chuva onde o tráfego é lento, porém o valor final da venda da soja é inferior ao de Paranaguá-PR.

Tabela 7 - Análise entre valor e distância

\begin{tabular}{cccc}
\hline Local de Venda & R\$ safra-frete & Distância / Km & Tempo de viagem \\
\hline Sorriso & $\mathrm{R} \$ 1.888 .558,75$ & 30 & 1 hora \\
Santarém & $\mathrm{R} \$ 1.828 .108,75$ & 1.700 & 54,48 horas \\
Paranaguá & $\mathrm{R} \$ 1.953 .058,30$ & 2.255 & 72,24 horas \\
\hline
\end{tabular}

Fonte: Resultados da pesquisa

Para tanto, verifica-se que a opção de comercializar a safra do produtor $\mathrm{X}$ da cidade de Sorriso, ao porto de embarque de Paranaguá-PR, é mais viável perante as demais opções estudadas. Apesar da média do preço da soja de Paranaguá-PR ser inferior à de Santarém-PA, a logística de transporte proporciona uma melhor economia escoando para Paranaguá-PR.

Ainda na Tabela 7, observa-se que apesar de a comercialização da soja no porto de embarque de Paranaguá-PR ser a alternativa viável perante as demais, o tempo de viagem é muito maior do que seria para Santarém-PA. Contudo, a melhor opção econômica realmente é ParanaguáPR, mas se for necessário uma maior rapidez no transporte, deve-se analisar esta questão também, onde em média um veículo percorre $750 \mathrm{~km} /$ dia.

\section{Considerações finais}

Verificou-se que, a viabilidade econômica de o produtor X comercializar sua safra de soja no porto de embarque de Paranaguá-PR, onde mesmo tendo uma média do valor da saca da soja inferior ao porto de Santarém-PA os valores com frete acabam por se sobressaírem, tornando assim, uma melhor vantagem econômica.

Considerando-se a produção da propriedade em estudo, a receita na opção de entregar a produção na própria cidade (Sorriso), seria de $\mathrm{R} \$ 1.888 .558,75$; na opção Paranaguá-PR o valor seria o de R\$ 1.953.058,30; e por fim, na opção Santarém-PA o valor final seria de e $\mathrm{R} \$$ $1.828 .108,75$. 
Os elevados custos com o transporte são, também, resultados das péssimas condições da rodovia BR-163. Mesmo sendo menor a distância entre Sorriso e Santarém em relação à opção Sorriso a Paranaguá resulta em $30 \%$ a mais no frete, devido às limitações de tráfego.

Para concluir, considerando o volume produzido em todo o município de Sorriso $(2,14$ milhões de toneladas na safra 2007/2008) e comercializando esse volume em Paranaguá, a receita tottal seria de $\mathrm{R} \$ 1.370 .313 .334,00$; comercializando em Santarém a receita seria representada por $\mathrm{R} \$ 1$ 1.294.343.334,00 e em Sorriso o total de R \$ 1.337.143.334,00. O resultado produziria um ganho de R \$ 75.970.000,00 entre as opções de comercialização de Paranaguá comparado com Santarém, ou um ganho de R\$33.170.000,00 de Paranaguá comparado com a comercialização em Sorriso.

\begin{abstract}
The research problem that this study covers is based on the condition of the soya producer of Sorriso city in Mato-Grosso, to has few alternatives to sell your production. However, this study searches to answer the following question: Which is the best alternative for farmers, to deliver your production in a multinational established in Sorriso, to deliver at the Port of Paranaguá or at the Port of Santarém? The methodology is characterized as quantitative. Although, it was developed a study case, that allows, the knowledge in wide manner and detailed process of logistical flow for the soya harvest in Sorriso. It was considered in this study, the production from 2000 to 2008. Also, it was collected informations with a transport company in Sorriso, to understand the historical lifting of the prices freight paid for the modal road, for the transport of grains, from Sorriso until the ports of Santarém and Paranaguá. It is observed that, Sorriso city is situated in central of Mato-Grosso, on km 742 of the road BR-163, on the sense Cuiabá-Santarém, at $420 \mathrm{~km}$ from the capital Cuiabá. Considering the production of the property in study, it was found that, the economic viability of the producer to trade the soya harvest at the departure port of Paranaguá-PR, has the best economic advantage.
\end{abstract}

Keywords: logistics; logistics corridor; flow of soya.

\title{
Referências
}

ABIOVE. Associação Brasileira das Industrias de Óleos Vegetais. Complexo Soja - Exportações. 2008. Disponível em: <http://www.abiove.com.br/exporta_br.html>. Acesso em: 30 set. 2011.

BADER, M. e SAVOIA, J. R. F. Logística da distribuição bancária: tendências, oportunidades e fatores para inclusão financeira. RAE - Revista de Administração de Empresas. São Paulo v. 53, n. 2, mar /abr. 2013. Disponível em: <http://rae.fgv.br/rae/vol53-num2-2013/logistica-distribuicao-bancaria-tendencias-oportunidades-fatores-para-inclusaof>. Acesso em: 02 out. 2013.

BALLOU, R. H. Logística Empresarial: transporte, administração de materiais e distribuição física. São Paulo: Atlas, 1993.

BERTAGLIA, P. R. Logística e gerenciamento da cadeia de abastecimento. São Paulo. Saraiva, 2003.

BERTAGLIA, P. R. Logística e gerenciamento da cadeia de abastecimento. $2^{\mathrm{a}}$ ed. Revista e atualizada. São Paulo. Saraiva, 2009.

BOWERSOX, D. J. CLOSS, D. J. Logística Empresarial: o processo de integração da cadeia de suprimento. São Paulo: Atlas, 2001. 
CAIXETA FILHO, J. V. GAMEIRO, A. H. Transporte e Logística em sistemas agroindustriais. São Paulo: Atlas, 2001.

CARGILL - Sorriso (MT), 2008.

CI- Soja - Centro de Inteligência da Soja. Novo recorde de produção de soja no Brasil sendo confirmado. Disponível em: <http://www.cisoja.com.br/downloads/Inf.\%20Conj.\%20de\%20SOJA-\%20Maio\%202010.pdf〉 . Acesso em: 30 abr. 2011.

CONAB. Companhia Nacional de Abastecimento. Corredores de Escoamento da Produção Agrícola: Corredor da BR-163. Disponível em: <http://www.conab.gov.br/conabweb/download/nupin/Corredor_Escoamento\%20BR163.pdf>. Acesso em: 30 set. 2011.

CORREA, V. H. C. RAMOS, P. A precariedade do transporte rodoviário brasileiro para o escoamento da produção de soja do Centro-Oeste: situação e perspectivas. Revista de Economia e Sociologia Rural. vol.48 no.2 Brasília Apr./June 2010. Disponível em: < http://www.scielo.br/scielo.php?pid=S010320032010000200009\&script=sci_arttext>. Acesso em: 30 abr. 2011.

DIAS, M. A. P. Administração de materiais: uma abordagem logística. São Paulo: Atlas, 2009.

EMBRAPA. Tecnologias de Produção de Soja Região Central do Brasil 2004. Disponível em: <http://www.cnpso.embrapa.br/producaosoja/SojanoBrasil.htm>. Acesso em: 17 ago. 2011.

FARIA, A. C. de; COSTA, M. de F. G. da. Gestão de custos logísticos. São Paulo: Atlas, 2011.

FRANCISCHINI, P. G. E. GURGEL, F. do A. Administração de materiais e do patrimônio. São Paulo: Cengage Laerning, 2010.

IGNÁCIO, A. A. V. DANTAS, L. M. BRAGA, M. E. BRITO, E. G. de; CARDOZO, V. G. Logística do escoamento da safra agrícola no Corredor Noroeste. IN: XVI SIMPEP - SIMPÓSIO DE ENGENHARIA DE PRODUÇÃO. Ensino de Engenharia de Produção: desafios, tendências e perspectivas, 16, 2009, Bauru/SP. Anais... Disponível em:

<http://www.simpep.feb.unesp.br/anais.php>. Acesso em: 02 out. 2013.

LACERDA, L. Armazenagem e localização de instalações. FLEURY, P. F. WANKE, P. FIGUEIREDO, K. F. (org). Logística Empresarial a perspectiva Brasileira. São Paulo: Atlas, 2009.

GOMES, C. F. S. Gestão da Cadeia de Suprimentos Integrada à Tecnologia da Informação. São Paulo: Pioneira Thomson Learnig, 2004.

GOMES, F. P. TORTATO, Ubiratã. Planejamento e gestão da logística reversa no setor de energia elétrica - um estudo de caso. Revista Gestão Industrial. Revista da Universidade Tecnológica Federal do Paraná. Ponta Grossa, Paraná, v.6 n.4, p. 197-214, 2010.

GRANDE CUIABÁ Notícias. Sorriso registrou a melhor safra de soja de todos os tempos. disponível em:<http://grandecuiaba.com.br/economia/20102011-sorriso-registrou-a-melhor-safra-de-soja-de-todos-os-tempos > Acesso em: 30 abr. 2011.

IBGE. Em 2010, safra nacional cresceu 11,6\%; para 2011, a estimativa é de queda de 2,5\%. Disponível em: <http://www.ibge.gov.br/home/presidencia/noticias/noticia_visualiza.php?id_noticia=1798\&id_pagina=1 >. Acesso em: 30 abr. 2011.

INPE. Mesmo sem chuvas regulares, MT começa plantar safra 2011/12 de soja. Disponível em: <http://www.inpe.br/noticias/namidia/img/clip24092011.pdf>. Acesso em: 27 set. 2011.

KEEDI, S. Transportes e Seguros no Comércio Exterior. São Paulo: Aduaneiras, 2000.

LEMOS, M. B. MARTINS, R. S. Corredor Centro-Leste: Sistemas de Transporte de Minas Gerais na Perspectivas dos Eixos de Desenvolvimento e Integração. Belo Horizonte, 2006. Disponível em:

<http://www.cedeplar.ufmg.br/pesquisas/td/TD\%20289.pdf>. Acesso em: 30 set. 2011.

MACHLINE, C. Cinco décadas de logística empresarial e administração da cadeia de suprimentos no Brasil. RAE -

Revista de Administração de Empresas. São Paulo v. 51, n.3, maio/ jun. 2011. Disponível em: 
<http://rae.fgv.br/rae/vol51-num3-2011/cinco-decadas-logistica-empresarial-administracao-cadeia-suprimentos-nobrasil>. Acesso em: 02 out. 2013.

MAGGE, J. F. Logística Industrial, São Paulo: Ed. Pioneira, 1999.

NOVAES, A. G. Logística e gerenciamento da cadeia de distribuição. Rio de janeiro: Elsevier, 2007.

PREFEITURA DE SORRISO. Disponível em:

<http://www.sorriso.mt.gov.br/?open=eJwzMjU00DE0NzfTMTYxsy9It01OLEpMLkktyiwuyUxOLFYrySzItzVRMzIx MNUxtDQ21jGzMAIAnX8PJw\%3D\%3D2417,1389,438.html>. Acesso em: 27 ago. 2011.

RICHARDSON, R. J. Pesquisa social: métodos e técnicas. São Paulo: Atlas, 2011.

SÉRIE AGRONEGÓCIOS. Cadeia produtiva da soja - volume 2. Disponível em:

<http://www.iica.org.br/Docs/CadeiasProdutivas/Cadeia\%20Produtiva\%20da\%20Soja.pdf>. Acesso em: 30 abr. 2011.

RODRIGUES, P. R. A. Introdução aos sistemas de transporte no Brasil e à logística internacional. $3^{\mathrm{a}}$ ed. São Paulo. Aduaneiras, 2003.

TRANSPORTADORA RODOGRANDE. Unidade de Sorriso-MT, 2008.

WANKE, P. F. Logística para MBA executivo em 12 lições. São Paulo: Atlas, 2010.

\section{Dados dos autores:}

Nome completo: Alexsandro Vanzella

Filiação institucional: PUCPR - Pontifícia Universidade Católica do Paraná

Departamento: Curso de Direito

Função ou cargo ocupado: Discente

Endereço completo para correspondência: Rua João Luiz Dias, 659, Bloco D, Apartamento 403.

Bairro Parque Cidade Nova. Maringá, Paraná, Brasil. CEP: 87023130.

Telefones para contato: (44) 9824-5537

e-mail: alexvanzella@hotmail.com

Nome completo: Carlos Jaelso Albanese Chaves

Filiação institucional: UEMS - Universidade Estadual de Mato Grosso do Sul

Departamento: Ciências Contábeis

Função ou cargo ocupado: Professor

Endereço completo para correspondência: Av. Marechal Floriano 567 Centro, Ponta Porã, Mato

Grosso do Sul, Brasil. CEP: 79900-000

Telefones para contato: (67) 8168-1002

e-mail: Jaelso@uems.br

Nome completo: Tarcisio Marcelo Menezes

Filiação institucional: Cesumar - Centro Universitário de Maringá 
Departamento: Administração

Função ou cargo ocupado: Professor

Endereço completo para correspondência: Rua Néo Alves Martins 3377 sala $5025^{\circ}$ andar Centro,

Maringá Paraná, Brasil. CEP: 87013-060

Telefones para contato: (44) 9991.5368

e-mail: tarcisio@interbusiness.com.br

Nome completo: Moysés Simão Kaveski

Filiação institucional: UEMS - Universidade Estadual de Mato Grosso do Sul

Departamento: Administração

Função ou cargo ocupado: Professor

Endereço completo para correspondência: Rua Emilio Dias Brandão No 55, Vila Santa Izabel, Ponta Porã, Mato Grosso do Sul, Brasil. CEP: 79900-000

Telefones para contato: (67) 9294.8103

e-mail: moyses@uems.br

Submetido em: 09/10/2011

Aceito em: 06/02/2013 